\title{
STUDY OF VIBRATED CONCRETE
}

\author{
By John Tucker, Jr., G. L. Pigman, E. A. Pisapia, and J. S. Rogers
}

\section{ABSTRACT}

Starting with a basic 1:2.2:3.8 mix (the ratio of cement to sand to gravel which was selected as desirable for ordinary placement methods), a series of mixes was developed in which the segregation caused by vibration, and which was manifested by the appearance of a mortar layer on the concrete, was progressively reduced by changes in proportioning. It was found that the segregation could be minimized by using an extremely dry mix or by adjusting the mortar content so that it did not exceed the voids in the large aggregate by more than approximately 15 percent.

The strength of the concrete could not be increased by vibration above that of the rodded cylinders unless the concrete was very dry, that is, with a slump of approximately zero. Decrease in water content beyond this point caused a further increase in strength of the vibrated specimens but a reduction in that of the rodded concrete. The additional strength caused by vibration was greatest at 7 days (earliest test age) and least at 1 year (latest test age).

Molds containing the concrete were vibrated at various amplitudes and frequencies for different durations. It was found that by sufficiently vibrating concrete with any combination of amplitude and frequency a strength was obtained which was not appreciably increased with further vibration.

The relative effectiveness of vibration with a stated amplitude and frequency was measured by the rapidity with which the concrete attained a given strength. It was found that the effectiveness of the vibration was roughly proportional to the acceleration, that is, to the amplitude and to the square of the frequency of the vibration.

\section{CONTENTS}

I. Introduction

II. Apparatus, materials, and tests

1. Vibrator

2. Materials

3. Tests: scope and methods

III. Development and design of mixes

IV. Test results $\ldots \ldots \ldots \ldots 0$

1. Influence of amplitude, frequency, and duration upon effectiveness of vibration

2. Influence of vibration on properties of concrete with varying water contents

(a) Strength... 584

(b) Solidity 587

(c) Surface condition 587

(d) Segregation

3. Energy required for compaction 590

V. Summary and conclusions

\section{INTRODUCTION}

The use of vibration to compact concrete is not new, vibrating tables having been used as early as $1890 .^{1}$ In 1906 the concrete in the test beams made by the U. S. Geological Survey and reported in

\footnotetext{
1 Sci. et ind. No. 14, p. 46 (February 1934).
} 
Bureau of Standards Technologic Paper T2 was placed by the aid of pneumatic vibrators. A short study of the problem was made by the National Bureau of Standards in 1915, but the strengths obtained with the concrete which had been vibrated into the molds were not greater than those obtained by the then common laboratory method of placing the concrete by ramming it with a heavy tamper. The potential increase in the strength of concrete due to vibration was not then apparent, and the studies were discontinued.

The method was first used to an appreciable extent during the World War. Independently, in 1917, M. Freyssinet, in France, and the U. S. Shipping Board applied the method to the construction of concrete ships. It was not, however, until about 1925 that the vibration of concrete came into extensive use.

Studies on the effect of vibration have already been made by others. ${ }^{2}$ Although the effectiveness of the vibration depends upon the amplitude and frequency, test data have been for the most part qualitative. ${ }^{3}$ It was the purpose of this investigation to determine the properties of concrete compacted into molds which were vibrated with known frequencies and amplitudes.

\section{APPARATUS, MATERIALS, AND TEST METHODS}

\section{VIBRATOR}

The vibrator is spring-suspended, as schematically shown in figure 1. The amplitude of vibration is a function of the eccentricity and

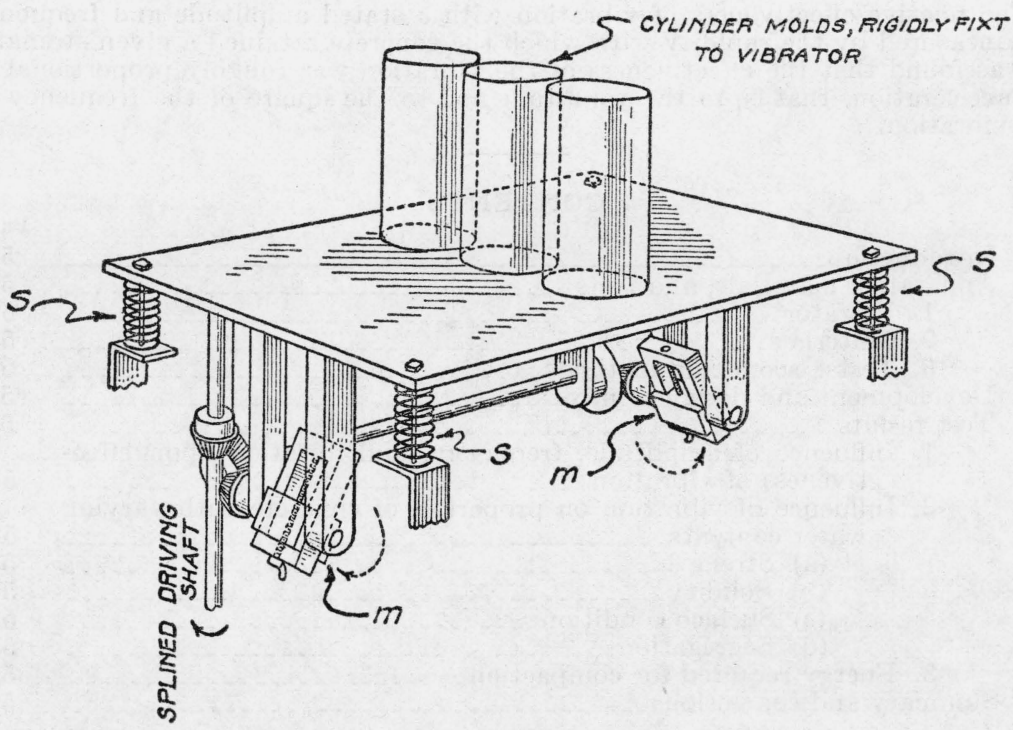

Figure 1.-Vibrator.

angular velocity of the rotating masses $(m)$, of the constants of the four springs $(S)$, and of the ratio of the magnitude of the two rotating

\footnotetext{
${ }^{2}$ For example, see bibliography, Proc. Am. Concrete Inst., p. 454 (1936).

3 At the time this investigation was begun there were no quantitative data. Articles have since appeared in Proc. Am. Concrete Inst., p. 528 (1935); Prof. Witbey, Proc. Highway Research Board (1935); Inst. Civil Engrs., London (March 1937), which present quantitative data.
} 
masses $(m)$ to the total mass of the machine (including that of the rotating masses, $m$ ).

The masses $m$ were adjusted closely to have the same eccentricity. The resultant horizontal component of the dynamic forces they exerted on the vibrator should have been zero, if the adjustment were perfect, but there was some horizontal vibration of the table, especially at the highest frequency. The machine vibrated the cylinder mold vertically, with a close approximation to simple harmonic motion.

The vibrator was designed so that the natural frequency, $4.4 \mathrm{vps}$ (vibrations per second), of the vibrator was well below the frequencies used in the tests. The forced-amplitude type was selected in order to eliminate the uncertainty of the amplitude at resonance.

\section{MATERIALS}

The aggregate was Potomac River sand and gravel. The sand had a fineness modulus of 2.8. The sand and the gravel each had a specific gravity of 2.65. The gravel was recombined from four sizes: no. 4 to $3 / 8$ in.; $3 / 8$ to $3 / 4$ in.; $3 / 4$ to 1 in.; and 1 to $1 \frac{1 / 2}{\text { in. The }}$ cement was of one lot of one brand of portland cement. It was stored in sealed metal drums.

\section{TESTS: SCOPE AND METHODS}

The proportions of the mixes are given in table 1 . The initial tests were made on mix $A$, a nominal 1:2:4 mix. Mixes $B$ to $G$ were developed through study of the segregation caused by vibration. Mix $G(1: 1.1: 4.9)$ of the same richness in cement to aggregate by weight as $A$, was of most unusual proportions, in which the mortar was just in excess of the voids in the coarse aggregate, and in which the segregation had thus been reduced. Mixes $B$ to $F$ were used in segregation and development studies only. The characteristics of mixes $A$ and $G$, both normally rodded into place and compacted by varying degrees of vibration, were determined over a wide range of water contents, as shown in figures 8 and 9 . The vibration characteristics (amplitude, frequency, and durations) used for compacting the concretes are shown in figure 3.

TABLE 1.-Proportions by weight of mixes of dry materials

\begin{tabular}{|c|c|c|c|c|c|c|c|}
\hline \multirow{3}{*}{ Mix } & \multicolumn{3}{|c|}{ Concrete } & \multicolumn{4}{|c|}{ Coarse aggregate } \\
\hline & \multirow{2}{*}{ Cement } & \multicolumn{2}{|c|}{ Aggregate } & \multirow{2}{*}{$\begin{array}{l}\text { No. } 4 \text { to } \\
3 / 4 \text { in. }\end{array}$} & \multirow{2}{*}{$\begin{array}{l}3 / 8 \text { to } 3 / 4 \\
\text { in. }\end{array}$} & \multirow{2}{*}{$\begin{array}{l}3 / 4 \text { to } 1 \\
\text { in. }\end{array}$} & \multirow{2}{*}{$\begin{array}{l}1 \text { to } 11 / 2 \\
\text { in. }\end{array}$} \\
\hline & & Fine & Coarse & & & & \\
\hline $\begin{array}{l}A \\
B \\
B \\
D \\
B\end{array}$ & $\begin{array}{l}1.00 \\
1.00 \\
1.00 \\
1.00 \\
1.00 \\
1.00 \\
1.00\end{array}$ & $\begin{array}{l}2.22 \\
2.00 \\
1.40 \\
\text { 1. } 56 \\
\text { 1. } 70 \\
\text { 1. } 66 \\
1.10\end{array}$ & $\begin{array}{l}\text { 3. } 80 \\
6.50 \\
\text { 4. } 60 \\
\text { 7. } 85 \\
\text { 7. } 37 \\
6.45 \\
\text { 4. } 90\end{array}$ & $\begin{array}{l}\% \\
20.0 \\
15.4 \\
15.6 \\
15.4 \\
16.8 \\
16.7 \\
15.3\end{array}$ & $\begin{array}{l}\% \\
30.0 \\
23.1 \\
23.0 \\
24.7 \\
26.1 \\
26.1 \\
23.1\end{array}$ & $\begin{array}{l}\% \\
20.0 \\
23.1 \\
23.0 \\
20.7 \\
20.5 \\
20.5 \\
23.1\end{array}$ & $\begin{array}{l}\% \\
30.0 \\
38.4 \\
38.4 \\
39.2 \\
36.6 \\
36.7 \\
38.5\end{array}$ \\
\hline
\end{tabular}

The batches for mixes $A$ to $F$, inclusive, were hand-mixed for 2 minutes, one batch for each cylinder. The batches for mix $G$, enough 
for 3 cylinders, were machine-mixed for 2 minutes. The slump test $^{4}$ was made in the usual manner. The flow was determined on concrete stirred into the mold, and recorded as the increase in diameter after $15 \frac{1}{1 / 8}$-in. drops in 10 sec on the 30 -in. flow table. ${ }^{5}$ It is to be noted that the concretes studied were all of very dry consistency, the wettest being drier than is normally used in construction (except, perhaps, for highways, or very special work). Because of the dryness of the concretes, the flow-table readings were less than those ordinarily encountered, reaching a minimum and then increasing with decreasing water content (figs. 8 and 9). The driest concretes (e. g. mix $A, C / W=2.50$ ), with water content less than that corresponding to minimum flow, may be said to have largely lost their plastic properties and to have a consistency similar to that of foundry moulding sand.

All concrete cylinders, 6 by 12 in., were made in watertight sheetmetal molds, the tops of which were sealed on with asphalt immediately after filling. The cylinders that were compacted by vibration were made by loosely filling the sheet-metal molds and superimposed hopper with a quantity of concrete which was almost enough, when compacted, to fill the molds.

The following combinations of frequencies and amplitudes were used: 21 vps at $0.043,0.095$, and 0.145 in.; 30 vps at $0.018,0.045$, and 0.095 in.; 42 vps at $0.01,0.026$, and 0.053 in.; 60 vps at $0.013,0.021$, and $0.04 \mathrm{in}^{6}$ The nominal duration of vibration was the elapsed time from the instant the vibrator attained the designated frequency, as indicated by a tachometer, to the time of shutting off the power. The rodded cylinders were molded by American Society for Testing Materials Standard Method C-39-33 (1933) test procedure. All specimens were made and stored in a laboratory maintained at $70 \pm 2^{\circ} \mathrm{F}$.

All strength-test specimens for each age and method of vibration were made in triplicate. On the date of test the sheet-metal molds were removed from the cylinders and the top and bottom surfaces of the cylinders ground to a plane surface. The dimensions and weights of the cylinders wer e determined immediately after making, and from these the weight of the concrete per unit volume and the solidity ${ }^{7}$ were calculated.

The segregation was usually manifested by an accumulation of mortar on top of the cylinder (see fig. 2). For convenience, the

\footnotetext{
4 Proc. Am. Soc. Testing Materials. Tentative Test Method 32, part 1, D-138-32T (1932).

s Proc. Am. Soc. Testing Materials. Tentative Test Method 36, part 1, C-124-36 T (1936).

6 These were the observed values obtained by microscopic measurement from lines made on borizontally moving cards by the sharp points of pencils rigidly attached to the vibrator. The greatest absolute variation of the observed values from the computed was about 0.007 in., and the greatest percentage variation was 18 percent, excluding, in both cases, the frequency of $60 \mathrm{vps}$. The rigidity of the machine was not adequate to eliminate flexure at $60 \mathrm{vps}$, and consequently secondary vibrations were set up. This emphasizes the necessity of special precautions in vibrator design and construction and also the necessity of experimentally checking the computed amplitudes and frequencies.

7 The solidity is the ratio of the sum of the bulk volumes of the particles of the dry materials to the volume of the concrete. It is computed from the equation:
}

$$
\text { Solidity }=\frac{W_{c}}{D_{c}}+\frac{W_{s}}{D_{s}}+\frac{W_{o}}{D_{0}}
$$

in which $W_{c}, W_{\varepsilon}$, and $W_{g}$ are the weights of cement, sand, and gravel in a unit volume of concrete, and $D_{0}$, $D_{\mathrm{a}}$, and $D_{\mathrm{g}}$ are the bulk densities of the cement, sand, and gravel particles, respectively, as computed from the equation:

$$
D=\frac{W_{d} \times W}{W_{w}-W_{i}}
$$

where $W_{d}$ is the weight of the dry material, $W_{t}$ is the weight of the water-saturated material in air, $W_{i}$ is its weight submerged in water, and $W$ is the weight of a unit volume of water. 
segregation was taken as the difference in cement content of the upper and lower halves expressed as a percentage of the content in the lower half. The determination of the proportions of the concrete in the segregation studies was made by the proposed American Society for Testing Materials method. ${ }^{8}$

The surface condition of all cylinders was recorded as the estimated total area of pitting, pockets, or honeycombing on the surface.

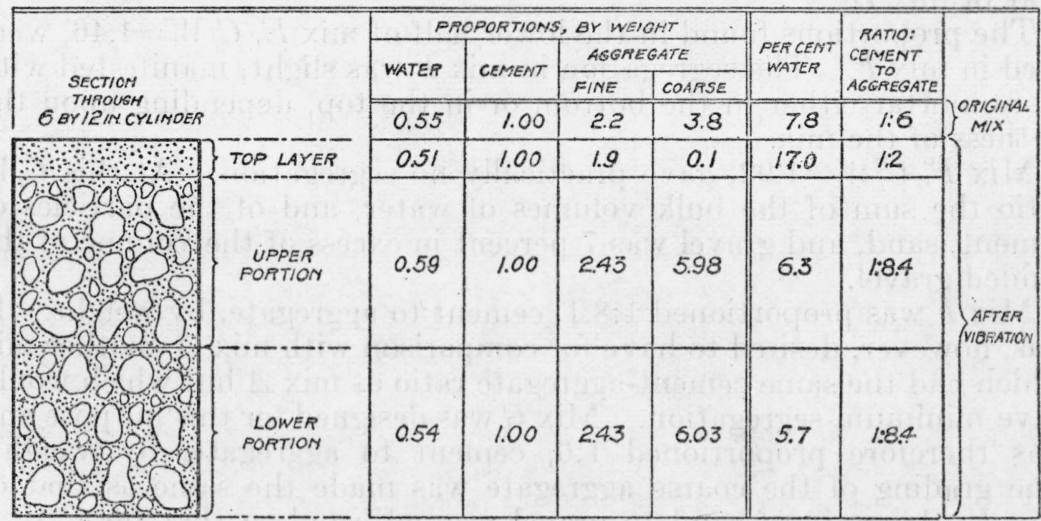

Figdre 2.-Segregation, mix $A, C / W=1.82$, after vibration.

\section{DEVELOPMENT AND DESIGN OF MIXES}

Table 1 gives the proportions of all mixes. Mix $A$, when made with the sand and gravel at hand, was well suited for laboratory use without vibration. The proportion of the several sizes of gravel was an arbitrary one which had been found satisfactory in previous Bureau studies.

Mix $A$, when vibrated, showed a distinct tendency to segregate in the wetter consistencies. A cylinder mold full of concrete from a batch of $\operatorname{mix} A, C / W=1.82$, by weight, was vibrated, and as the mortar rose to the top of the cylinder more and more of the batch was added. The displaced mortar flowed over the top of the mold until the cylinder was apparently a uniform compact mass with no mortar excess on top. This mass was analyzed and the same proportions of dry materials were used in mix $B$. In this and subsequent proportionings, the amounts of the four gravel sizes were chosen to the nearest whole percentage of the total mix.

Mix $C$ was selected to have the same cement-aggregate ratio as $\operatorname{mix} A$, and the same sand-gravel ratio and the same grading of coarse aggregate as mix $B$.

There was still pronounced segregation in vibrated specimens of $\operatorname{mix} C$, for $C / W=1.82$. Mix $D$ had the same cement-sand ratio and the same grading of coarse aggregate as the bottom half of the vibrated cylinders of mix $C$, but the ratio of mortar to coarse aggregate was reduced so that the mortar would exactly fill the voids in the rodded coarse aggregate.

It was found that $\operatorname{mix} D, C / W=1.43$, also segregated but in the reverse manner from the previous mixes. The bottom half of the

\footnotetext{
' Proc. Am. Soc. Testing Materials 31, Part 1, 383 (1931).
} 
cylinder contained a larger portion of mortar than the top, thus indicating a mortar deficiency in mix $D$.

The proportions in the lower half of mix $D$ were used in mix $E$. The segregation of mix $E, C / W=1.46$, was in the same direction as in mix $D, C / W=1.43$, i. e., the lower half of the cylinder contained more mortar than the upper half. The difference in the proportions in the upper and lower halves was, however, very small, and about a fourth that of mix $D$.

The proportions found in the lower half of $\operatorname{mix} E, C / W=1.46$, were used in mix $F$. The segregation in mix $F$ was slight, manifested with more mortar either in the bottom or in the top, depending upon the wetness of the mix.

Mix $F, C / W=1.92$, gave practically no segregation. At this $C / W$ ratio the sum of the bulk volumes of water, and of the particles of cement, sand, and gravel was 7 percent in excess of the volume of the rodded gravel.

Mix $F$ was proportioned $1: 8.1$, cement to aggregate, by weight. It was, however, desired to have for comparison with mix $A$ another mix which had the same cement-aggregate ratio as mix $A$ but which would have minimum segregation. Mix $G$ was designed for this purpose and was therefore proportioned 1:6, cement to aggregate, by weight. The grading of the coarse aggregate was made the same as that of mix $F$; the ratio of sand to gravel was adjusted so that for $C / W=$ 2.50 , the bulk volume of water, cement, sand, and gravel was made, as in mix $F, C / W=1.92,7$ percent more than the bulk volume of the rodded coarse aggregate. It was found that the segregation in mix $G, C / W=2.1$, (the same water content as mix $D, C / W=1.43$ ) was approximately the same as the segregation of this latter batch but in the opposite direction. Mix $G$ appeared to be the mix with a cementaggregate ratio of $1: 6$ in which the segregation was a minimum, for even the most severe vibration.

\section{TEST RESULTS}

Complete test data were obtained only on mix $A$. Data on mix $G$ were obtained for vibration periods of 30 and $90 \mathrm{sec}$ only. Data were obtained for mix $C$ for only one $C / W$ ratio $(2.50)$. Mixes $B, D, E$, and $F$ were used as steps in the determination of the mix with minimum segregation.

\section{INFLUENCE OF AMPLITUDE, FREQUENCY, AND DURATION UPON EFFECTIVENESS OF VIBRATION}

Figure 3 summarizes the strength-test results. It is apparent that with the exception of $\operatorname{mix} A, C / W=2.50$, and $\operatorname{mix} G, C / W=3.20$, vibration for the shortest duration was as effective as vibration for the longest duration in developing strength in the concrete. It can also be seen that the application of the vibration for the longest test periods (up to $90 \mathrm{sec}$ ) did not cause a reduction in strength.

Data on mix $A, C / W=2.50$, are given in detail in figure 4 . It is apparent from this figure that the various combinations of amplitudes and frequencies differed in their efficacy, as indicated by the strength of the concrete. From the results it is seen that vibration at $42 \mathrm{vps}$ and 0.01 -in. amplitude was the least effective, and that in most cases 

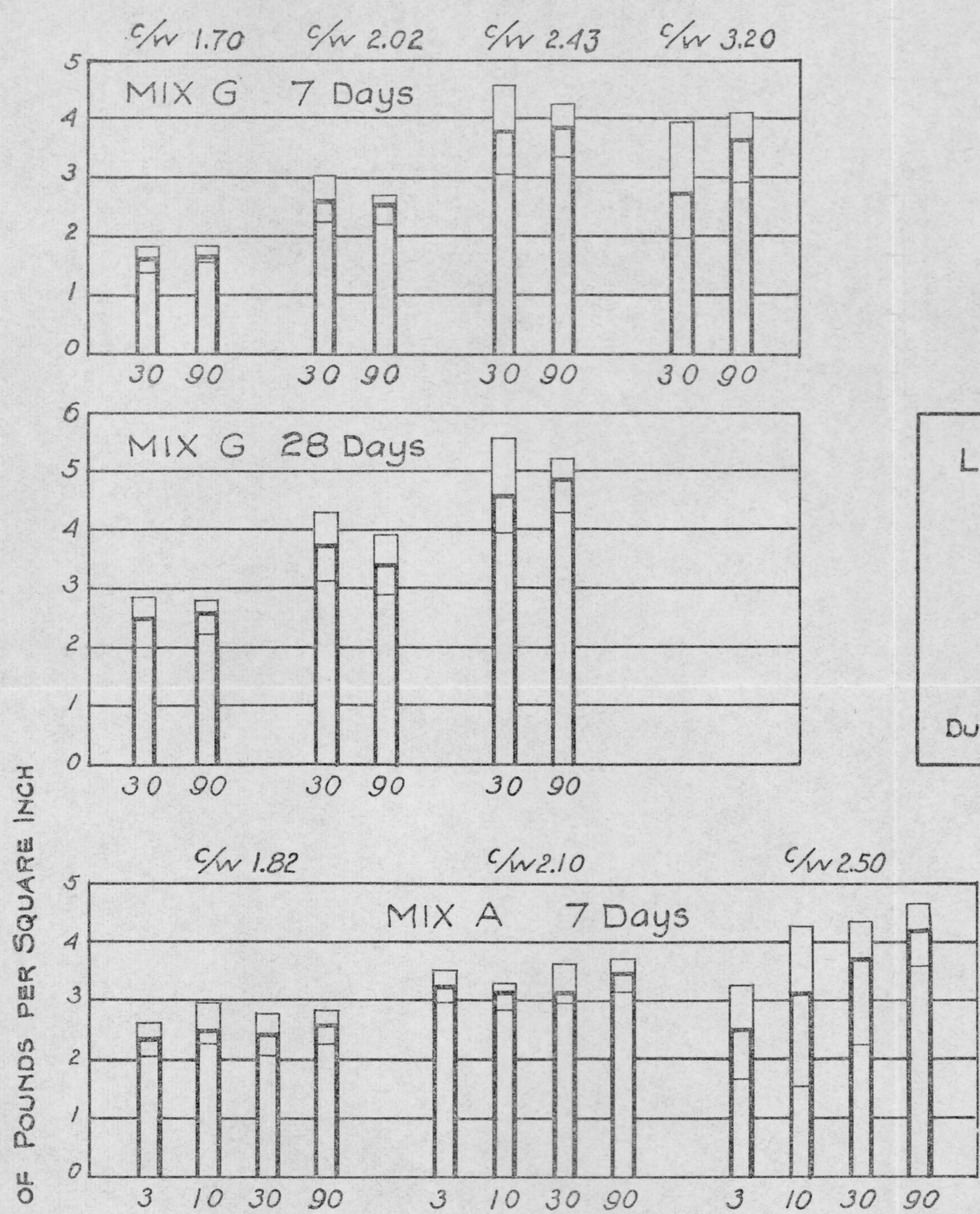

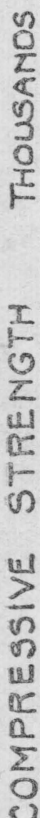

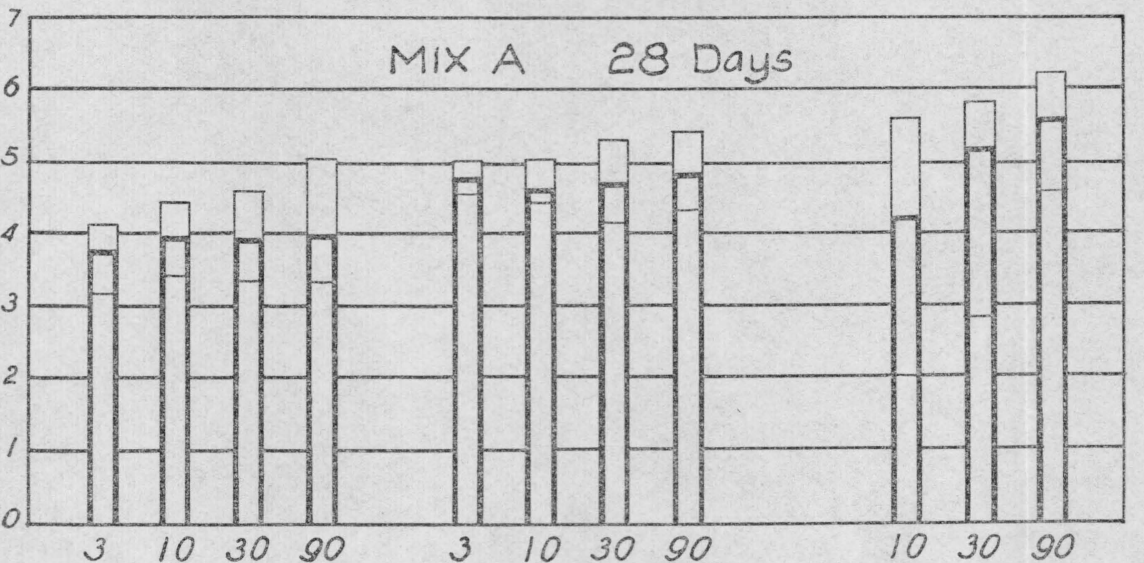

$\sum^{n}$

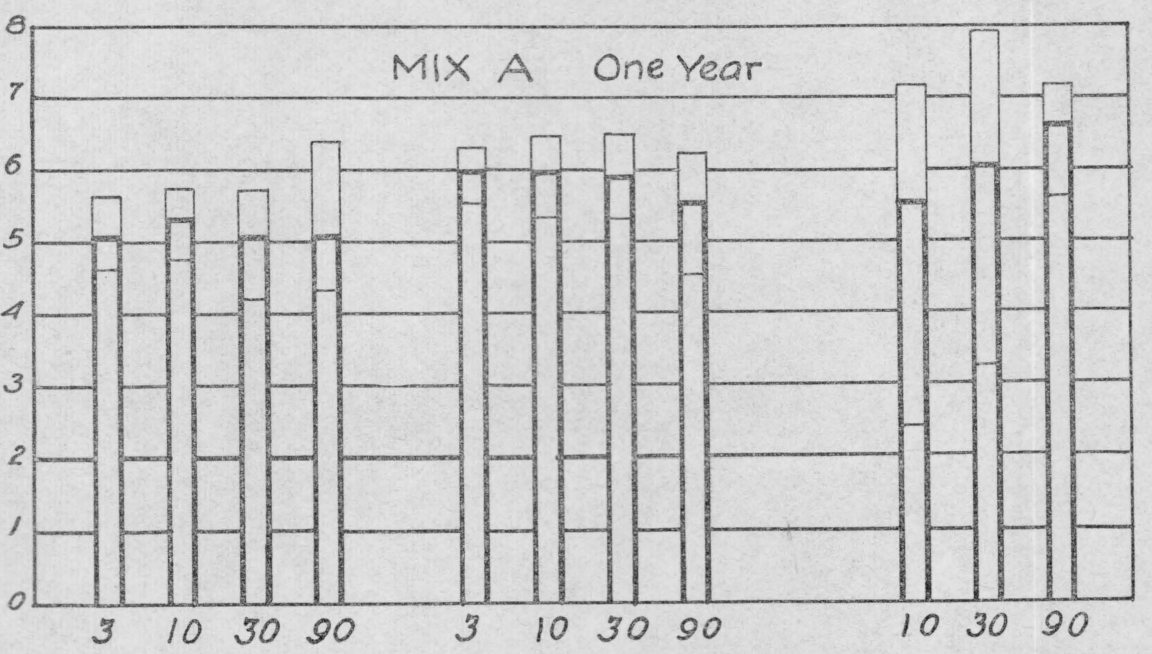

FIGURE 3.-Strengths of mixes $A, C$, and $G$, vibrated.
MIX C - 7DAYS

$c / w 2.50$
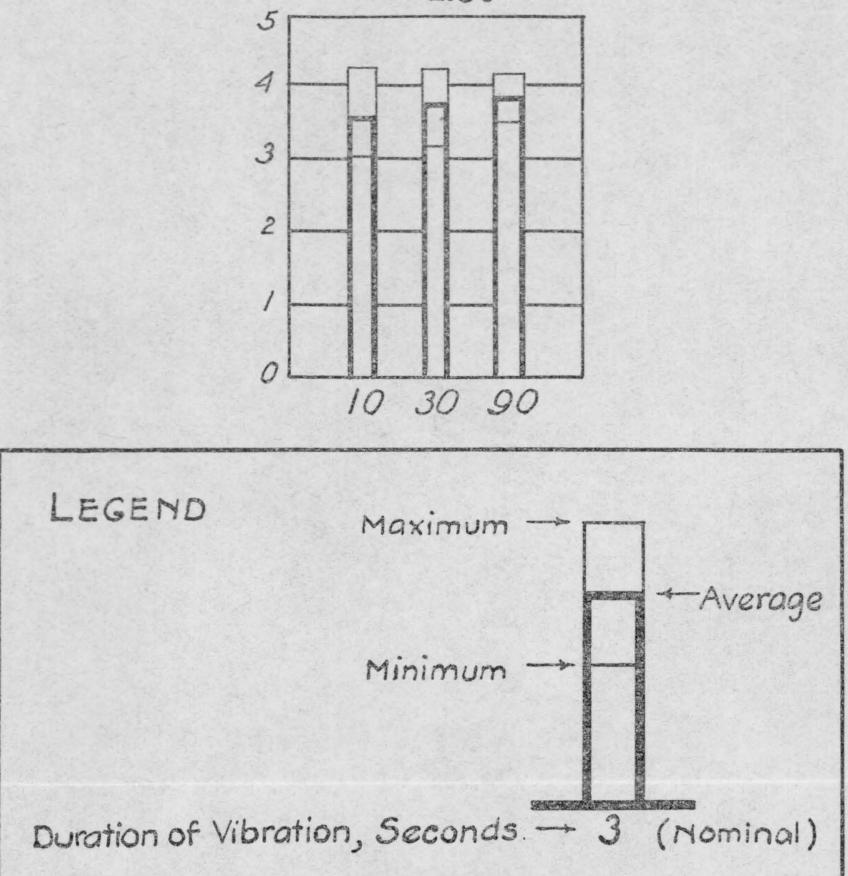

NOTES

The values given in the figure are, except as noted below, the average of specimens vibrated at all frequencies and amplitudes given in Fis 4.

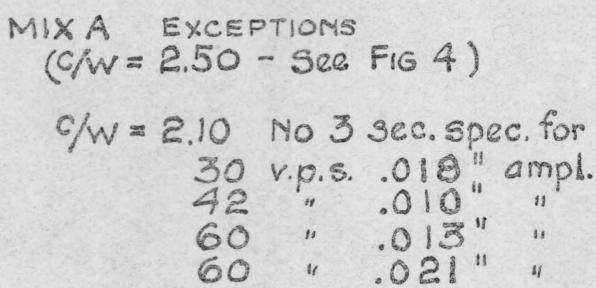

$c / w=1.82$ No 3 sec. spec. for 42 v.ps $012^{\prime \prime}$, and 60 v.p.s..025"

MixC $C / W=2.50$. The following ONLY:

$\begin{array}{llc}\text { ONLY: v.p.s } & .095^{\prime \prime} \text { ampl. } & 90 \mathrm{sec} \\ 30 & .018^{\prime \prime} & 30 \\ 30 & .095^{\prime \prime} & 90 \\ 42 & .010^{\prime \prime} & 30 \$ 90 \\ 42 & .026^{\prime \prime} & 90 \\ 42 & .053^{\prime \prime} & 90 \\ 60 & .021 " & 90\end{array}$

MIX G EXCEPTIONS.

$C / W=2.50$ No spec. for

21 v.p.s., $0.145^{\circ 1} \mathrm{mpl}$, 90 Sec.

$C / w=2.10$

30 v.p.s, $.095^{\prime \prime}$ ampl, 90 sec at 28 bays. 


$$
\begin{aligned}
& M I X A \\
& c / w=2.50
\end{aligned}
$$

EACH VALUE IS THE AVERAGE OF THREE TEST CYLINDERS.

\section{LEGEND}

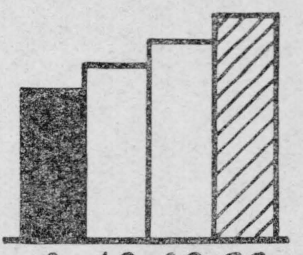

DURATIOM OF VIBRATION - SECONDS 31030 9O NOMINAL

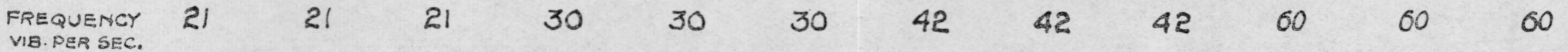

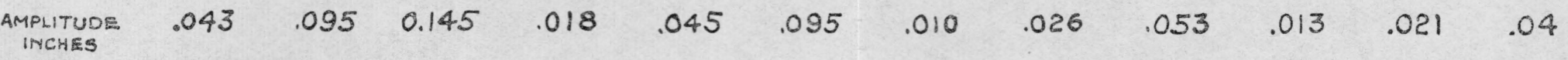
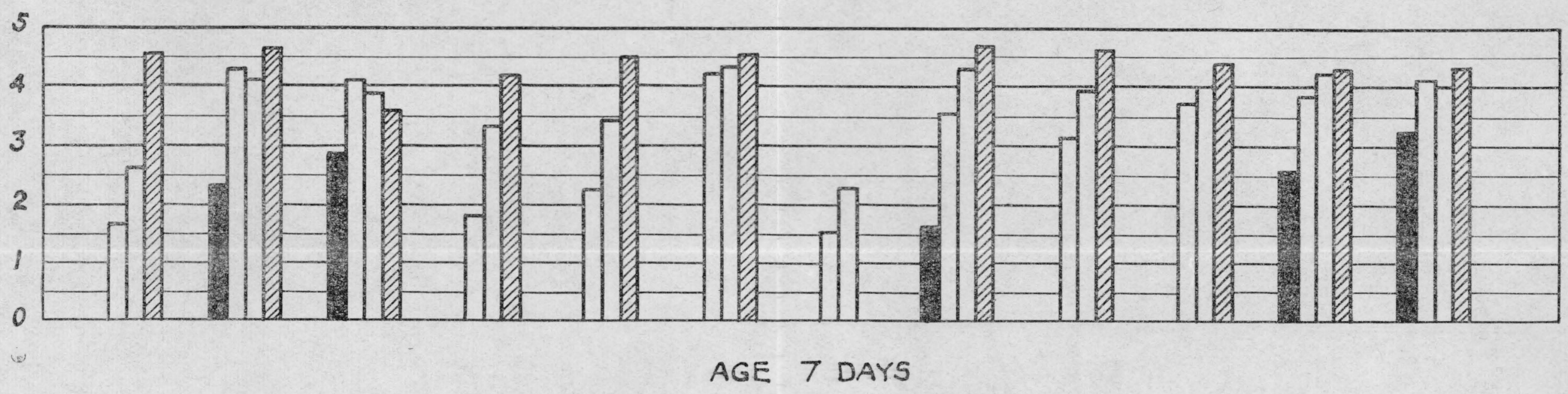

AGE 7 DAYS$$
\text { 要 }
$$

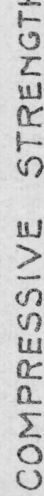
$\begin{array}{ll}5 & 5 \\ 2 & 4 \\ 2 & 3 \\ \frac{1}{2} & 2 \\ 0 & 1 \\ & 0\end{array}$ La 
the concrete was still increasing in strength even at the end of $90 \mathrm{sec}$ of vibration. On the other hand, it appears that for some combinations of amplitude and frequency (such as $60 \mathrm{vps}, 0.04$-in. amplitude) the increase in strength due to vibration was practically completed in $10 \mathrm{sec}$ or less.

In order to study further the effect of amplitude and frequency, figures 5 and 6 were drawn. ${ }^{9} \quad$ The curves showing increase in strength

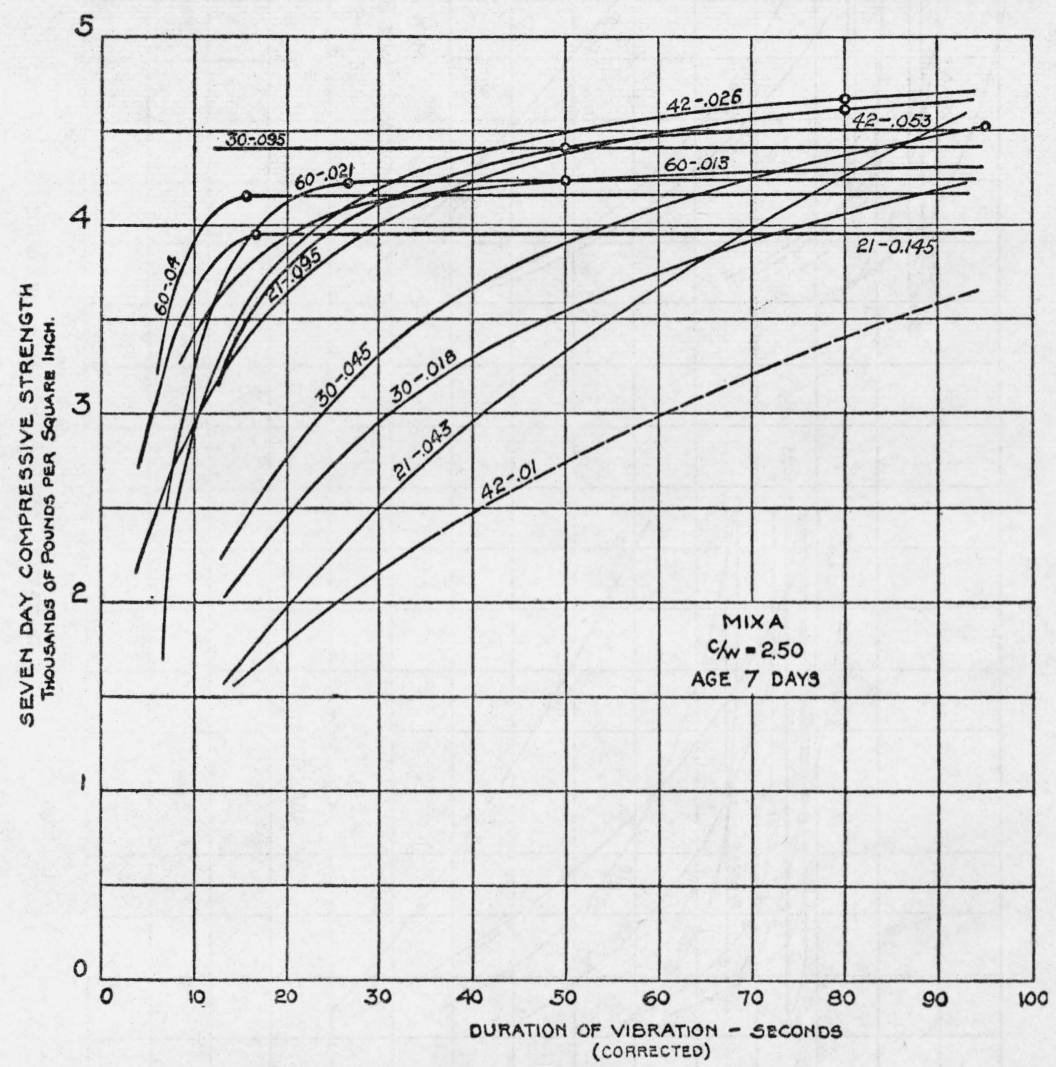

Figure 5.-Relation of strength and duration of vibration.

7 day strength mix $A, C / W=2.50$

Vibration characteristics shown in the form $42-0.01$ indicate a frequency of $42 \mathrm{vps}$ with an amplitude of 0.01 in.

with duration of vibration indicate the tendency for strength to increase rapidly at first, then less and less rapidly as the strength approaches a limiting value for the particular concrete with a fixed water content. The optimum strength was defined as that strength beyond which the increase, with continued vibration, was negligible.

The relative efficacy of different combinations of frequency and amplitude may be expressed by the reciprocal of the time required to attain a given strength, such as the strength of the rodded cylinders of

9 The time-frequency curves of starting and stopping the vibrator were determined. Corrections computed from these curves were added to the nominal durations of vibration, such revised durations being designated as the "corrected duration of vibration", and plotted in figures 5, 6, and 7. The data points were omitted in figures 5 and 6 to avoid confusion. In a few instances inconsistent points were given smaller weight in obtaining the curves. 


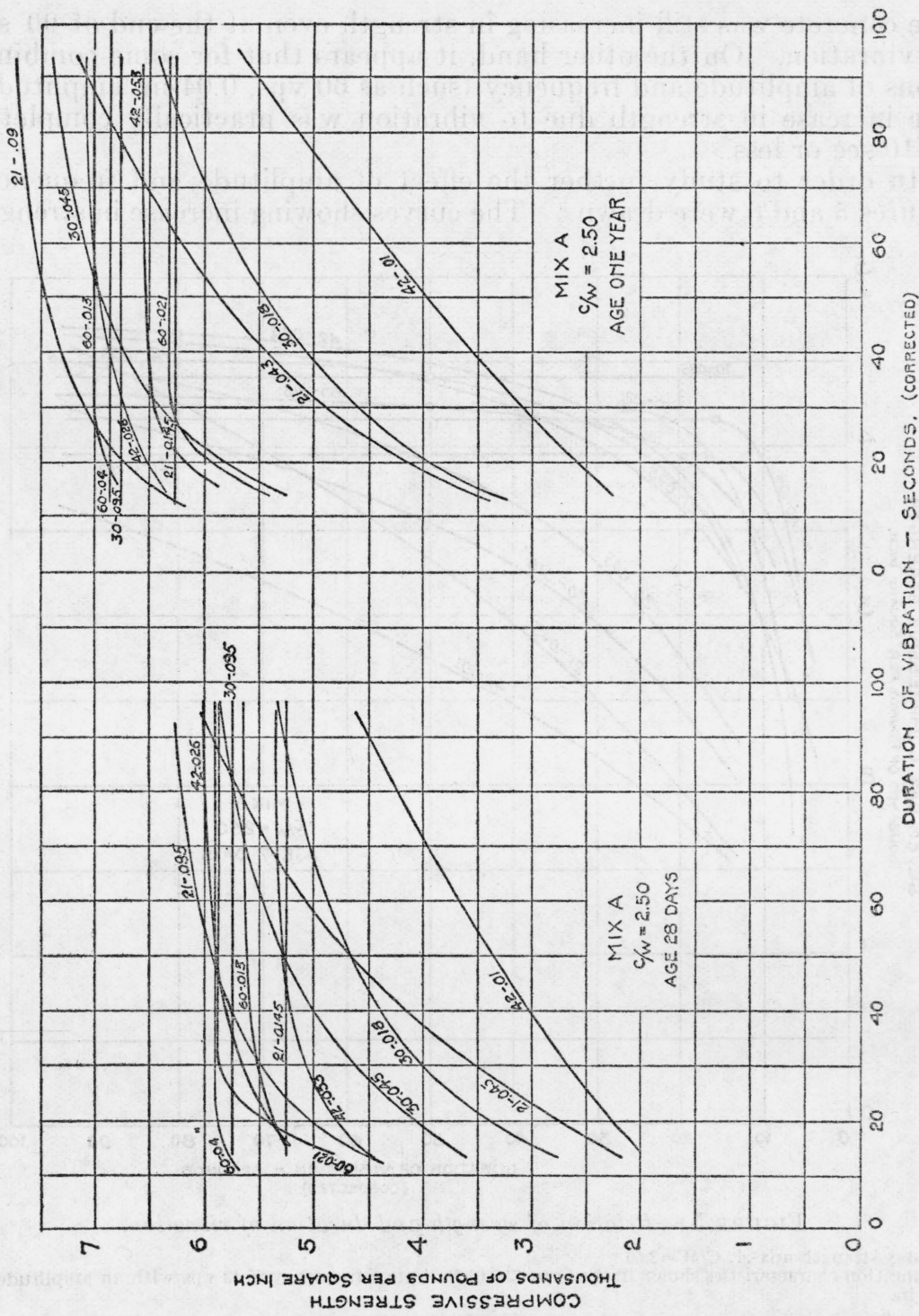

FIGURE 6.-Relation of strength and duration of vibration.

28-day and 1-year strengths, $\operatorname{mix} A, C / W=2.50$.

Vibration characteristics shown in the form $42-0.01$ indicate a frequency of $42 \mathrm{vps}$ with an amplitude of 0.01 inch.

equal age and $C / W$ ratio. Before tests were started it was assumed that the vibrational efficacy would be a function of the vibrational acceleration. This is proportional to the amplitude and to the square of the frequency.

In the preparation of the vibrated concrete specimens used in this study there were apparently present some variables not present in the rodded concrete specimens, which variables account for the greater spread in the results obtained in the vibrated-cylinder tests beyond 
that ordinarily encountered in studies of concrete. Consequently, the correlation of results was not as good as might be desired. However, from a careful examination of the data it appeared that, in accord with the original assumption, the effectiveness of the vibration was, to a first approximation, in integral powers of the variables, given by the relation

$$
t=\frac{k}{r n^{2}}, \text { or } t r n^{2}=k \ldots
$$

where

$t=$ duration of vibration, in seconds.

$r=$ amplitude of vibration, in inches.

$n=$ frequency in vibrations per second.

$k=$ parameter the value of which depends upon the degree of compaction reached by the concrete.

Figure 7 shows curves representing eq 1 for two values of $k$, together with the sets of points representing data for each of these values of $k$.

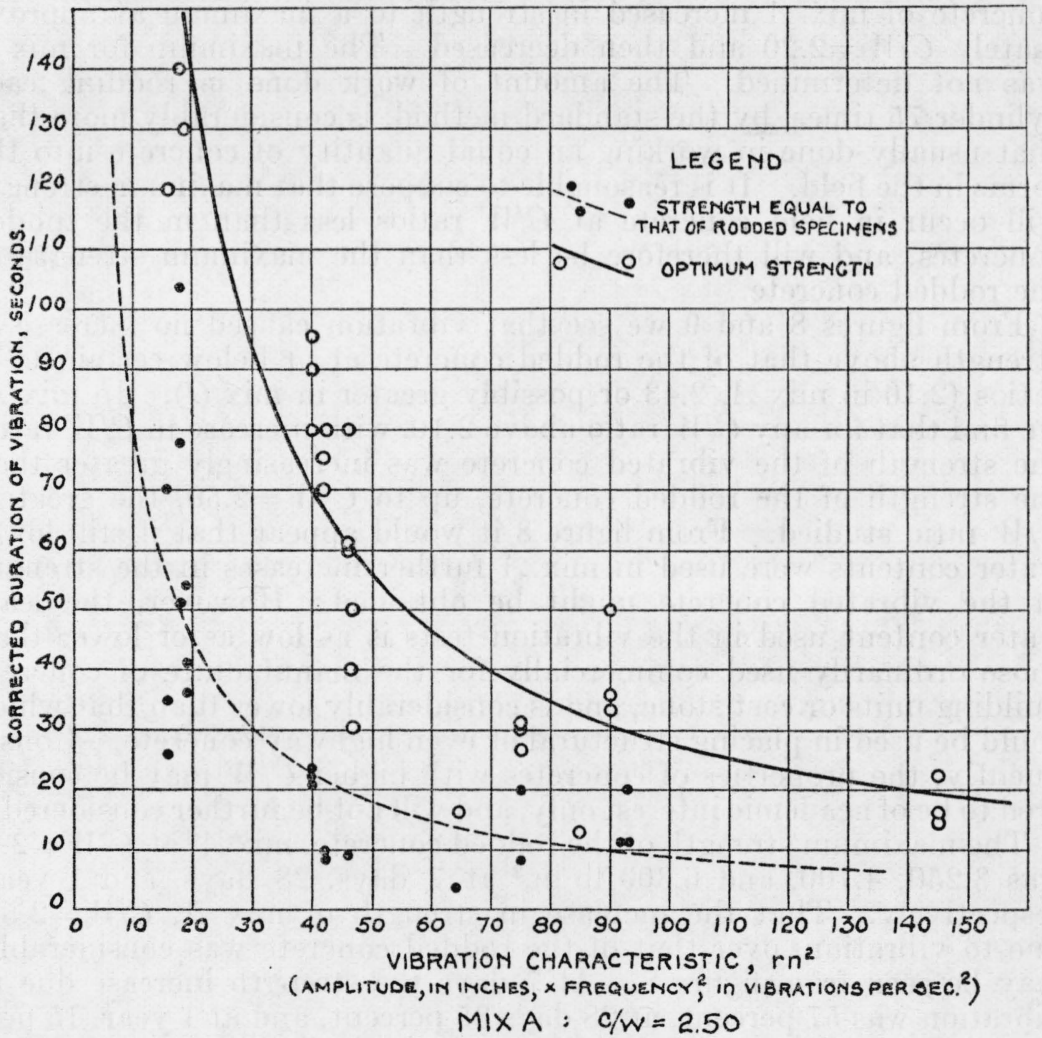

FigURE 7.-Graph of equation 1.

Data for all three test ages are assembled in this figure. The set of dots represents the durations of vibration required to develop strengths equal to those of rodded specimens of equal age and equal $C / W$ ratio. The dotted line gives the curve representing eq 1 best fitting 
these points. The set of circles represents the durations required to attain optimum strength, the solid line giving the curve representing eq 1 best fitting these points. Since there were only a few cases in which the specimens definitely attained a condition such that continued vibration could be interpreted as producing absolutely no increase in strength, the durations of vibration required for attaining optimum strength were taken as those durations beyond which the increase in strength with continued vibration was slight. The points indicated by circles in figure 5 were selected for computing the circles which represent the optimum strengths in figure 7 . Only about twothirds of the curves in figures 5 and 6 lent themselves to the selection of such points.

\section{INFLUENCE OF VIBRATION UPON PROPERTIES OF CONCRETES WITH VARYING WATER CONTENTS}

(a) STRENGTH

Figure 8 indicates that with decrease in water content the rodded concrete of $\operatorname{mix} A$ increased in strength to a maximum at approximately $C / W=2.20$ and then decreased. The maximum for mix $G$ was not determined. The amount of work done in rodding each cylinder 75 times, by the standard method, is considerably more than that usually done in working an equal quantity of concrete into the forms in the field. It is reasonable to suppose that maximum strength will occur in field concrete at $C / W$ ratios less than in the rodded concretes, and will therefore be less than the maximum strength of the rodded concrete.

From figures 8 and 9 we see that vibration caused no increase in strength above that of the rodded concrete at or below certain $C / W$ ratios (2.10 in mix $A, 2.43$ or possibly greater in mix $G$ ). In mix $A$, we find that for any $C / W$ ratio above 2.10 , with increase in $C / W$ ratio, the strength of the vibrated concrete was increasingly greater than the strength of the rodded concrete, up to $C / W=2.50$, the greatest $C / W$ ratio studied. From figure 8 it would appear that if still lower water contents were used in mix $A$ further increases in the strength of the vibrated concrete might be obtained. However, the least water content used in the vibration tests is as low as or lower than those ordinarily used commercially for the manufacture of concrete building units or cast stone, and is considerably lower than that which could be used in placing structural or even highway concrete. Consequently, the properties of concretes with higher $C / W$ may be considered to be of academic interest only, and will not be further considered.

The maximum strength of the rodded concrete, $\operatorname{mix} A$, at $C / W=2.2$, was $3,250,4,700$, and $6,300 \mathrm{lb} / \mathrm{in}^{2}$ at 7 days, 28 days, and 1 year, respectively. That the increase in strength of $\operatorname{mix} A, C / W=2.50$, due to vibration, over that of the rodded concrete was considerable, may be seen from figure 8. At 7 days the strength increase due to vibration was 57 percent, at 28 days 35 percent, and at 1 year, 15 percent. The difference in the effects at the various ages is striking. Not alone was the percentage increase much larger at 7 days, but the absolute increase in strength was greater at the earlier ages-1,600 $\mathrm{lb} / \mathrm{in} .^{2}$ at 7 days and $950 \mathrm{lb} /$ in. $^{2}$ at 1 year. 


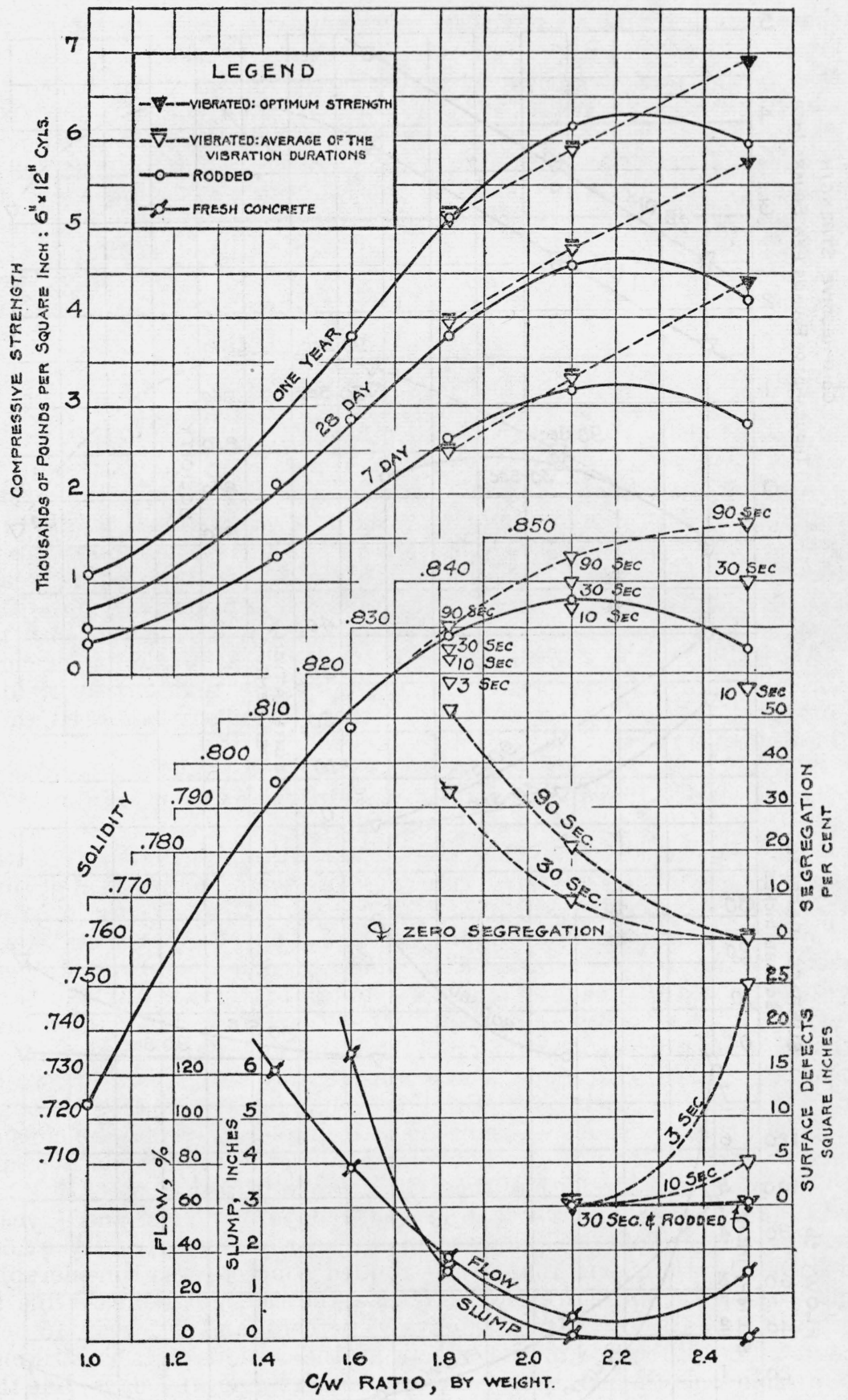

Figure 8.-Characteristics of mix A.

The values for the vibrated concretes are averages from figure 4. 


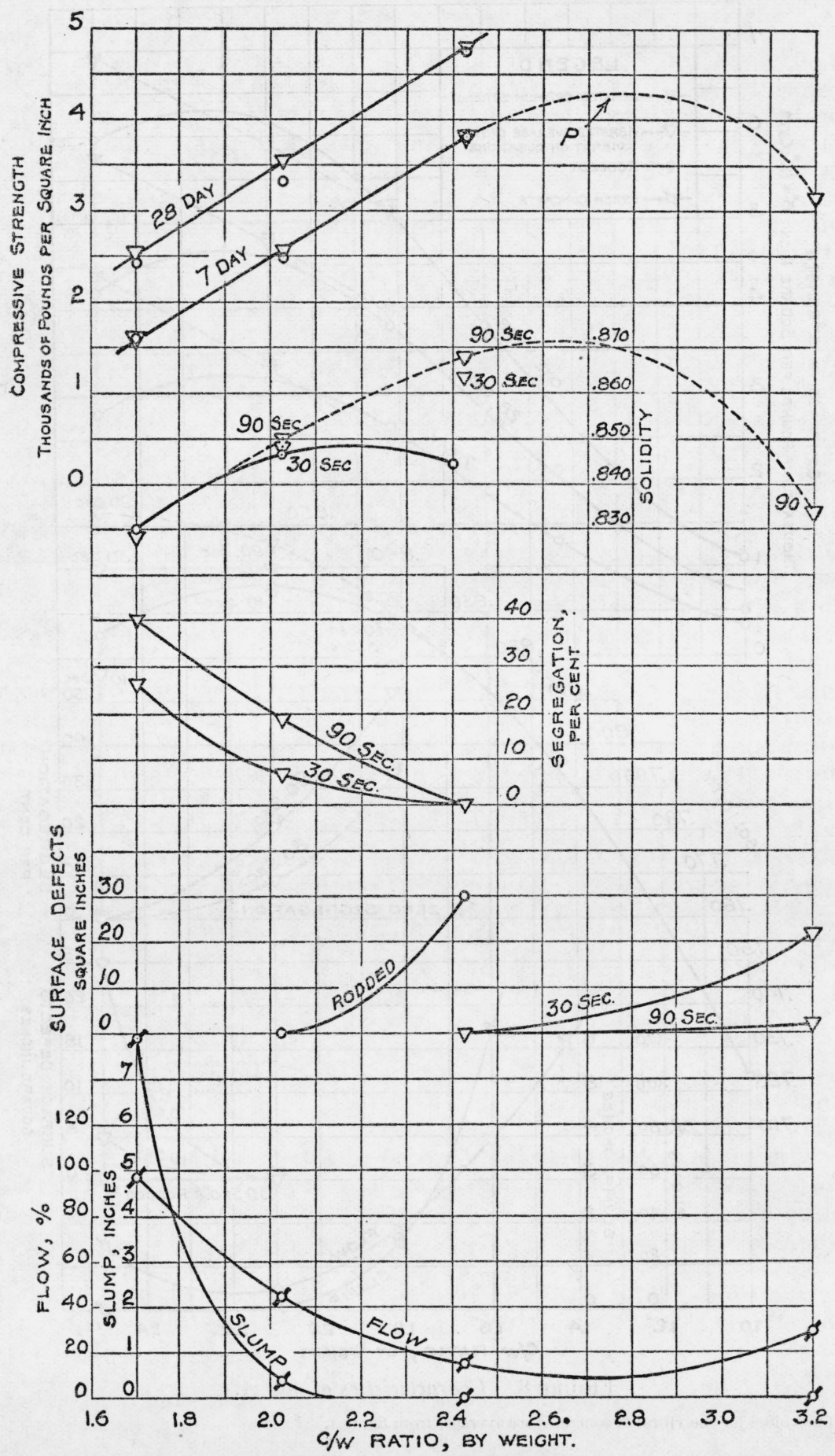

Figure 9.-Characteristics of mix G.

The values for the vibrated concretes are from figure 3 . See legend of figure 8 . 
The optimum strength ${ }^{10}$ of the vibrated concrete, mix $A, C / W=$ 2.50, was $4,400,5,800$, and $6,900 \mathrm{lb} / \mathrm{in}^{2}{ }^{2}$ at 7 days, 28 days, and 1 year, respectively. In comparing the strength of $\operatorname{mix} A, C / W=2.50$, vibrated, with the strength of the rodded concretes of the same $C / W$ ratio, it must be borne in mind that unless vibration were resorted to in field construction much more water would be necessary to permit satisfactory placement. Therefore, the increase in strength of the vibrated concrete, due to lower water content and vibration, above the strength of field concrete, not drier than, say, for example, $C / W=1.82$, would be still more pronounced.

Within the range of flows approximately from 35 to 100 the strengths of mix $A$ and of mix $G$ rodded concretes, of equal flow, were equal. Within this range of flow values, vibration at any combinations of duration, amplitude, and frequency gave the same strength concrete as that developed by the rodded concrete.

\section{(b) SOLIDITY}

It should be borne in mind that some concretes, such as mix $A$, $C / W=1.82$, were so wet that pronounced segregation occurred, and therefore the value of solidity given is an average value for the cylinder, which included the concrete in the main portion of the cylinder, plus the very dissimilar mortar layer on top. (See fig. 2.)

The solidity of the rodded concretes, figure 8 , increased with decrease in water content, attaining a maximum for mix $A$ at approximately the $C / W$ ratio $(2.2-)$ at which the maximum rodded concrete strength was obtained. The solidities obtained at various periods of vibration are also shown in the figures. For mix $A$ at $C / W=1.82$, the maximum solidity developed by vibration was practically the same as that obtained by rodding. With decrease in water, beyond this point, the greatest solidity developed by vibration was increasingly above that of the rodded concrete, the maximum attained value of the solidity, 0.853 , for the vibrated concrete being at $C / W=2.50$.

The solidity of the rodded specimens of mix $G$ (fig. 9) had the same trend as that of mix $A$, increasing with increasing $C / W$, to a maximum solidity of approximately 0.85 at a $C / W$ ratio of 2.2 , then decreasing. The solidity of mix $G$ vibrated specimens continued to increase up to a $C / W$ ratio apparently somewhat greater than 2.5 , the solidity being approximately 0.87 at this $C / W$ ratio for $90 \mathrm{sec}$ of vibration. Thirty seconds of vibration, on the average for all combinations of frequency and amplitude, was almost as effective as $90 \mathrm{sec}$, showing that the compaction was very rapid in this mix.

The specimens of mix $G$, both those rodded and those thoroughly compacted by vibration, had maximum solidities greater than any obtained in mix $A$. Thus, the maximum solidity of mix $G$, vibrated, was 0.871 , and that estimated for mix $A$, vibrated, was 0.853 .

Figure 10 gives the strength of $\operatorname{mix} A, C / W=2.50$, vibrated, plotted against solidities. It may be seen that there is a trend at any age for the strength to increase at a greater rate as solidity increases.

\section{(c) SURFACE CONDITION}

The surface condition was measured by the estimated area of surface defects, expressed as a percentage of the cylindrical surface. A surface with less than 2 or 3 percent of defects was considered satis-

10 The mean optimum strengths shown in figure 8 for $C / W=2.50$ are the averages of the strengths of mix $A$ concrete subjected to 90 sec. of vibration for all frequencies and amplitudes (except 420-0.012).

$19521-37-7$ 
factory. The appearance of all rodded cylinders of mix $A$ was quite satisfactory, principally because each cylinder was carefully rodded around the periphery.

There was no significant difference in the surface condition of mix $A$ cylinders vibrated with any combination of frequency and amplitude for any one period of time, except for the cylinders, $C / W$ greater

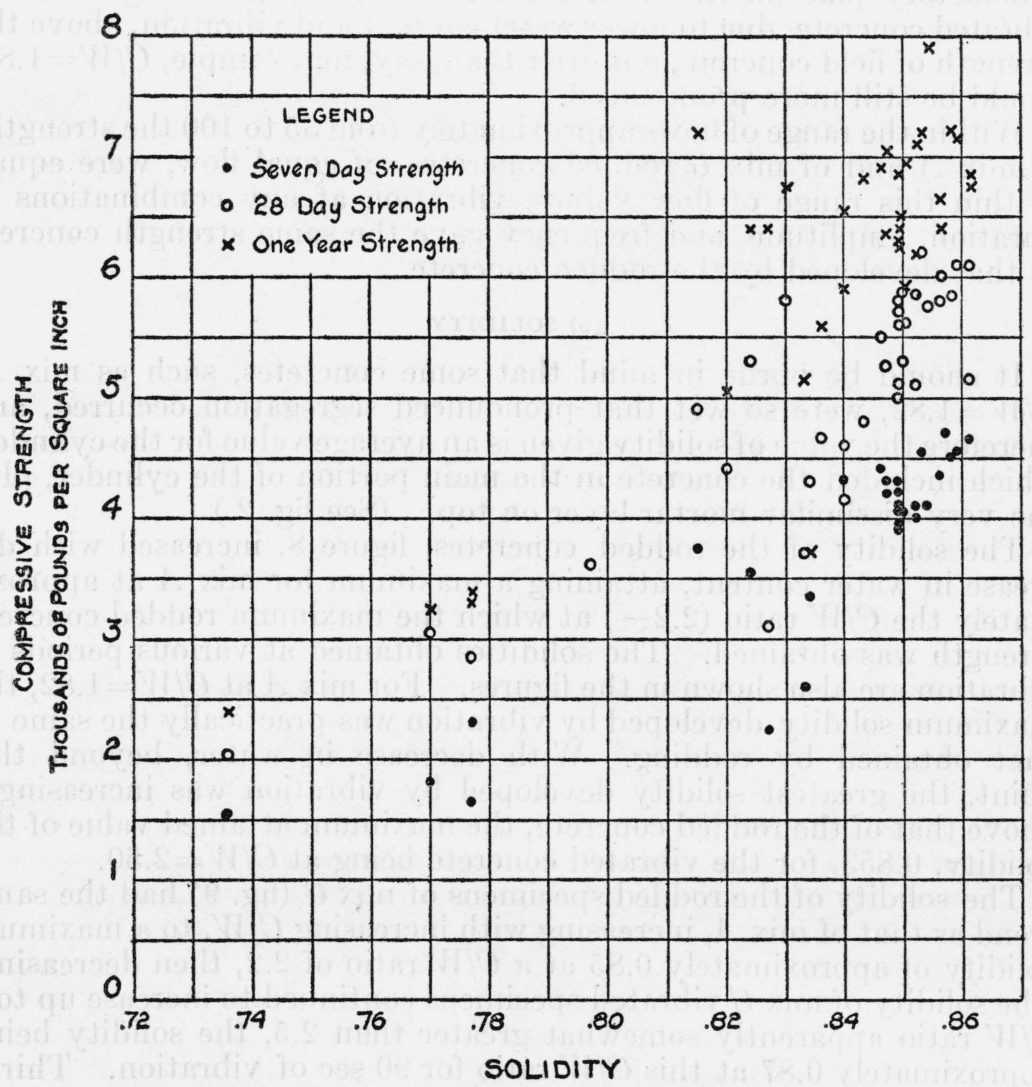

FIGURE 10.-Relation of solidity and compressive strength.

$\operatorname{Mix} A, C / W=2.50$, vibrated.

than 2.10 , vibrated at the least effective combination of frequency and amplitude for 10 sec or less (see fig. 8). With increase in $C / W$ beyond 2.10 , the amount of vibration necessary to produce a satisfactory surface rapidly increased, and for $C / W=2.50$ at least $30 \mathrm{sec}$ of vibration was necessary, for the least effective vibration.

The condition of the rodded specimens of mix $G$ rapidly approached an undesirable condition with decrease in water beyond $C / W$ ratio= 2.10 , the cylinders at $C / W=2.43$ being badly honeycombed, with about 15 percent of the area so affected. Only $30 \mathrm{sec}$ of vibration was necessary to reduce the surface defect to zero for $C / W=2.43$. 
The surfaces of mixes $A$ and $G$ specimens were practically perfect for all vibrational treatments, for $C / W$ ratios of 2.10 or less in mix $A$ or 2.43 or less in mix $G$.

\section{(d) SEGREGATION}

When in mix $A$ the $C / W$ was 1.82 or 2.10 , there was apparently a slight tendency for the segregation to be greater for the more efficient combinations of amplitude and frequency. (Data not given.) The tendency appeared to be very secondary to the duration of vibration or to the water content, and the average values for all vibration combinations of $n$ and $r$ have been plotted in figures 8 and 9 .

There was no appreciable segregation in the vibrated specimens of $\operatorname{mix} A$, at $C / W=2.50$. With an increased water content, however, segregation occurred, as shown in figure 8. The increase in segregation became more and more pronounced with increase in water content; thus at $C / W=2.10$, the average segregation at 90 sec was 21 percent, whereas at $C / W=1.82$, the 90 sec segregation was 52 percent. The rapidity with which segregation occurred was also much greater with higher water contents; thus for $C / W=2.10$, the 30 sec segregation was 9 percent, or only 43 percent of that of the $90 \mathrm{sec}$ segregation, whereas for $C / W=1.82$, the 30 sec segregation was 33 percent, or 63 percent of that of the 90 sec segregation. Thus the desirability of holding the water content to the very minimum was demonstrated, if segregation is to be avoided. In practice, if a mix equivalent to $\operatorname{mix} A, C / W=1.82$ were used, before the concrete at a distance from the vibrator were compacted, greatly excessive segregation would occur in the zone immediately surrounding the vibrator.

It was observed that a wet mortar appeared on the surface of the vibrating concrete cylinder, $\operatorname{mix} A, C / W=1.82$ and 2.10 , within a few seconds after the start of vibration; optimum strength was found to be developed within the same time. Consequently, the instant of appearance of such wet mortar appears to be an indication of the completion of compaction, vibration beyond this time merely causing more segregation.

Table 2 gives the original proportions of mixes $A, F$, and $G$, together with the extreme range in proportions of the lower halves of cylinders of those concretes vibrated in their wetter consistencies to the point where no appreciable further segregation occurred.

It appears that unless a very dry mix, which will not segregate under the most severe vibration, be used, the proportions must be carefully selected. Thus, the $F$ mix, $1: 8.1$, was the richest mix in which segregation was negligible in the moderately wet ${ }^{11}$ mixes (flow=35). In both mixes $A$ and $G$ the cement and sand were not radically separated by vibration but the mortar in excess of that required to fill the voids in the coarse aggregate moved upward. The mortar of mix $F$ was present in 17 percent excess of the amount required to fill the coarse aggregate voids. (See table 2).

\footnotetext{
11 For vibration.
} 
TABLE 2.-Comparative segregation of mixes $A, G$, and $F$ with approximately equal $C / W$ ratios

\begin{tabular}{|c|c|c|c|}
\hline \multirow{2}{*}{ Mix } & \multicolumn{2}{|c|}{$\begin{array}{c}\text { Proportions of cement, sand, gravel, and water, by weight, in } \\
\text { lower half of cylinder }\end{array}$} & \multirow{2}{*}{$\begin{array}{l}\text { Volume of } \\
\text { mortar ex- } \\
\text { pressed as } \\
\text { percentage } \\
\text { of voids in } \\
\text { dry rodded } \\
\text { aggregate } 1\end{array}$} \\
\hline & Original & Limits after vibration & \\
\hline A.. & $\left\{\begin{array}{l}1: 2.2: 3.8: 0.55 \\
1: 2.2: 3.8: 0.55\end{array}\right.$ & $1: 2.4: 5.3: 0.49$ & $\begin{array}{l}250 \\
166\end{array}$ \\
\hline & 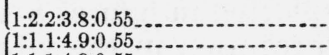 & $1: 2.4: 6.0: 0.52$ & $\begin{array}{l}151.0 \\
134\end{array}$ \\
\hline G.. & $\{1: 1.1: 4.9: 0.55$ & $\begin{array}{l}1: 1.2: 6.9: 0.56 \\
\text { to }\end{array}$ & 99.8 \\
\hline$F$ & 1:1.1:4.9:0.55 & $\begin{array}{l}1: 1.5: 6.1: 0.51 \\
\text { change negligible }\end{array}$ & $\begin{array}{l}119 \\
117\end{array}$ \\
\hline
\end{tabular}

1 Assuming no air voids in mortar.

\section{ENERGY REQUIRED FOR COMPACTION}

With even the least effective vibrational treatment used for specimens of $\operatorname{mix} A, C / W=2.10$ ( $n=21, r=.045$ in.), optimum strength was attained at 3 sec or less, as shown by the minimum values in figure 3. It required more than $90 \mathrm{sec}$ of vibration to compact specimens of $\operatorname{mix} A, C / W=2.50$, (fig. 5), vibrated with this same frequency and amplitude, sufficiently to obtain optimum strength. Since the former duration was only 3 percent of the latter it is obvious that in the first case only approximately 3 percent as much electrical energy was expended in operating the vibrator as in the latter.

The energy which the vibrator would have required to obtain optimum strength in specimens with $C / W=1.82$ cannot be estimated from the test data, but it was apparent, from observation, that less time was required than for the compaction of specimens with $C / W=$ 2.10. All of the cylinders of both $C / W$ ratios attained optimum strength at even the shortest vibration duration. Mix $A, C / W=2.50$, specimens required much more time to obtain optimum strength than the specimens of $\operatorname{mix} G, C / W=2.43$, the latter with but little more water. Hence it may be concluded that, for equal cementwater ratios, specimens of mix $G$ required less time for compaction, and therefore less energy was consumed in operating the vibrator.

\section{SUMMARY AND CONCLUSIONS}

This paper describes the results of tests on concrete specimens of which the mold was subjected approximately to simple harmonic vertical vibrations of known frequencies and amplitudes. This vibration differed from that effected with portable commercial vibrators, because in the case of the latter, the amplitude of vibration rapidly decreases as the distance from the vibrator increases. The amplitude, even in close proximity to vibrators of the portable type, is much less than the amplitude of the freely suspended vibrator, since attaching the vibrator to the form or immersing it in the concrete greatly reduces the amplitude. It is to be carefully noted that the amplitude of vibration quoted in the following conclusions refers to the amplitude of the mold. Moreover, it appears impractical by vibration to obtain 
strengths in structural concrete as high as those obtained with the driest mixes studied in this investigation. Such dry mixes can be vibrated commercially only in the manufacture of cast stone and prefabricated concrete building units. As the mixes are made wetter not only do they lose strength but the tendency to segregate increases at an increasing rate with the water content.

The tests warrant the following conclusions:

1. A vibrated concrete proportioned $1: 2.2: 3.8$ by weight (mix $A$ ), in which Potomac River sand and 11/2-in. gravel were used (an ideal mix for ordinary use without vibration) underwent pronounced segregation, even at a consistency extremely dry for ordinary use (flow of 35 ), and at the least effective vibration treatment. This segregation was exhibited as an accumulation of a layer of mortar on the surface of the concrete.

2. For the concretes with $1 \frac{1}{2}$-in. maximum size aggregate the segregation was reduced by decreasing the sand-gravel ratio to about 0.22 (mix $G-1: 1.1: 4.9)$ and was eliminated, with any sand-gravel ratio, when the mix was made excessively dry $(C / W=2.50$, zero slump, and water content less than that required for minimum flowsee fig. 8). Segregation was also minimized by proportioning the mix $1: 1.7: 6.5(\operatorname{mix} F)$, which latter alternative permitted the use of sufficient water to give the concrete a flow of 35 . In this case the volume of cement, sand, and water exceeded that of the voids in the dry rodded aggregate by 17 percent, and the sand-gravel ratio was 0.26 .

3. For the normal 1:2.2:3.8 mix, no increase in strength over that of rodded specimens was developed by vibration until the water content had been reduced to $C / W=2.1$, which gave approximately minimum flow. With further decrease in the water content to that of $C / W=2.5$, (an abnormally dry mix) the strength of the vibrated concrete continued to increase, although the strength of rodded concrete of the same $C / W$ ratio decreased. The greatest strengths obtained by vibration, which occurred with $\operatorname{mix} A$ at $C / W=2.50$, were 4,400 , 5,800 , and $6,900 \mathrm{lb} / \mathrm{in}^{2}{ }^{2}$ at 7 days, 28 days, and 1 year, respectively. These strengths were considerably greater than the maximum strength obtained with the rodded specimens. It is to be noted that the percentage increase was greatest at 7 days, the increase being less at 28 days and still less at 1 year. For flows between 35 and 100 the strengths of the vibrated and rodded specimens of mix $A$ were equal (fig. 8). The same is true for mix $G$ (fig. 9). Within this flow range the strengths of mixes $A$ and $G$ were equal.

4. The solidities of the rodded and vibrated specimens of mix $A$ for equal $C / W$ ratios were the same for water contents as low as approximately $C / W=1.8$, and the same was true for $\operatorname{mix} G$ to a water content as low as that in $C / W=2.0$. With lower water contents the solidity of the specimens vibrated to compaction was greater than that of the rodded specimens.

5 . The surface appearance of the concretes was excellent for water contents down to those corresponding to $C / W=2.1$ for mix $A$, and $C / W=2.4$ for mix $G$. With decrease in water content, the amount of surface defects of the concrete, unless thoroughly compacted, rapidly increased. Those specimens that were vibrated to optimum strength, even for the driest consistencies used, had a satisfactory appearance. 
6. The effectiveness of the vibration was defined as the reciprocal of the time required to obtain a concrete of given strength and was roughly proportional to the maximum vibrational acceleration. This acceleration is proportional to the amplitude and to the square of the frequency. The increase in strength with vibration continued with the duration of the vibration, the increase being slower and slower, until a strength was attained which did not materially change with further vibration. This value is referred to herein as the optimum strength.

7. If the vibrational acceleration is a measure of the efficacy in developing strength, then for a fixed acceleration, the energy required varies inversely as the frequency of the vibration, or directly as the square root of the amplitude.

8. The time required to vibrate $\operatorname{mix} A, C / W=2.50$ to optimum strength with any assigned frequency and amplitude was approximately 30 times as great as that required to vibrate the same mix with $C / W=2.10$ to optimum strength. For equal $C / W$ ratios, considerably less time was required to compact $\operatorname{mix} G$.

9. Those mixes with a low ratio of fine to coarse aggregate required a much shorter duration of vibration to obtain optimum strength than mixes with a normal sand-gravel ratio. A mix which required a relatively short duration of vibration, and which had low segregation, was proportioned so that the total of the bulk volumes of water, cement, and fine aggregate was 17 percent greater than the volume of voids in the rodded coarse aggregate. (Mix $F: 1: 1.7: 6.5$.)

G. L. Pigman assisted in the design of the vibrator, and with E. A. Pisapia and J. S. Rogers made all tests. John Tucker, Jr., designed the vibrator, supervised the investigation, and wrote the paper. The authors gratefully acknowledge the advice of $\mathrm{P}$. H. Bates, in general charge of the investigation, especially for his recognition of the importance of quantitative studies of segregation.

Washington, July 1, 1937. 